\title{
A Construção do "Real" e Práticas Discursivas: o Poder nos Processos de Institucionaliz(ação)
}

\author{
Alketa Peci \\ Marcelo Milano Falcão Vieira \\ Stewart R. Clegg
}

\section{RESUMO}

A partir de uma crítica das bases epistemológicas e ontológicas do neo-institucionalismo, este artigo defende a potencialidade da aplicação da perspectiva pós-estruturalista, particularmente aquela apresentada por Michel Foucault, à abordagem institucional. Essa proposta teórica - que incorpora uma dimensão negligenciada nas análises institucionais, especialmente, no campo das organizações (o poder) - apresenta a vantagem de contribuir para uma melhor compreensão das dinâmicas de institucionalização. Para isso é preciso operar a partir da superação da dicotomia objetividade/subjetividade, tão presente nos estudos institucionais. Por fim, são rediscutidos os processos de institucionalização, tomando por base o novo referencial e destacando-se por que determinadas práticas se institucionalizam. Ao propor que os processos institucionais ocorrem dentro de campos discursivos, o argumento apresentado é o de que tais processos servem à produtividade das relações de poder nesses campos. Práticas que são institucionalizadas são práticas que funcionam, ou seja, práticas necessárias e úteis ao exercício do poder.

Palavras-chave: poder; institucionalização; discurso.

\begin{abstract}
Starting with a critique of the epistemological and ontological bases of neo-institutionalism, in this article we defend the potential for the application of post-structuralist perspectives, particularly that presented by Michel Foucault, and the pragmatic perspective, represented here by the works of William James and Richard Rorty, to the institutional approach. We contend that this theoretical approach, which incorporates a dimension traditionally overlooked in institutional analyses, especially in the field of organizations, namely power, has the advantage of contributing to an enhanced comprehension of the dynamics of institutionalization. In order to achieve this, it is necessary to start from the standpoint of overcoming the objectivity-subjectivity dichotomy, so often found in institutional studies. Lastly, we re-assess institutionalization processes using the new reference standard, highlighting why certain practices become institutionalized. By contending that institutionalization processes take place within discursive fields, our proposition is that these are abetting the productivity of the power relationships, which are present in these fields. Practices that are institutionalized are practices that work, in other words, they are practices, which are both necessary and useful to the exercise of power.
\end{abstract}

Key words: power; institutionalization; discourse. 


\section{INTRODUÇÃO}

O novo institucionalismo é uma corrente em moda não apenas na área de estudos organizacionais, mas também em áreas como administração pública, sociologia, economia e nos estudos culturais. De certa maneira, essa abordagem se posiciona contra os pressupostos básicos da escola racional, que se guiam pela ontologia reducionista do individualismo e pela epistemologia empiricista do economicismo, assim como do funcionalismo estrutural (McSwite, 1998).

No entanto é difícil captar os pressupostos paradigmáticos dessa abordagem caracterizada pela ausência de um microfundamento coerente de ação. Powell e DiMaggio (1990) reconhecem essa falta e ressaltam que abordagens interpretativas como o construtivismo social de Berger e Luckmann, a etnometodologia de Garfinkel, a fenomenologia de Schutz, o cognitivismo de Simon, ou até mesmo os esquemas conceituais de Bourdieu e de Giddens são possíveis candidatos a um microfundamento de ação para o novo pensamento institucional.

Paralelamente, a agenda empírica do novo institucionalismo é caracterizada por centrar a pesquisa nos chamados processos de estruturação de campos organizacionais, demonstrando uma visão reducionista da análise institucional ao não enfatizar sua formação. Esta mesma perspectiva se detém mais no papel das instituições, deixando a desejar em termos de análise dos processos de institucionalização, no sentido de investigar as dinâmicas da institucionalização e, mais importante, por que determinadas práticas se institucionalizam e outras não.

Neste artigo, é defendida a potencialidade da aplicação da perspectiva pósestruturalista, particularmente aquela apresentada por Michel Foucault, à abordagem institucional.

O artigo está estruturado em seis seções, além desta introdução. Considerando as limitações previamente apontadas em termos de falta de um microfundamento de ação para a teoria institucional, uma imersão paradigmática torna-se necessária. Por isto, na primeira parte, são analisadas as chamadas perspectivas oficiais na base do novo institucionalismo, com destaque para a contribuição do construtivismo social representado por Berger e Luckmann e da etnometodologia de Garfinkel. Em seguida, são discutidos os conceitos de reificação, instituição e institucionalização, considerados centrais nessas abordagens. Na terceira parte, é ressaltado que a problemática da dicotomia objetividade/subjetividade está na base das diferenças existentes entre as abordagens analisadas, em termos de conceituação das acepções de reificação, instituição e institucionalização. A 
proposta teórica aqui apresentada se baseia no não reconhecimento dessa dicotomia, enraizada no senso comum e no modo de pensar e fazer ciência. Fundamentalmente, a vantagem desse novo pressuposto está na aplicação de um referencial teórico alternativo ao estudo dos processos de institucionalização. Em seguida, é ressaltado que o conceito de discurso em Foucault opera com base nesse mesmo pressuposto ontológico, podendo ser integrado na compreensão das dinâmicas de institucionalização. O conceito de praticabilidade ou funcionalidade revela-se fundamental para o entendimento dessas dinâmicas. É retomada, então, a análise da dicotomia objetividade/subjetividade para ressaltar a dimensão política dessa divisão, reconhecida na perspectiva foucaultiana. Por fim, são novamente discutidos os processos de institucionalização, a partir do novo referencial proposto, com destaque para as práticas que se institucionalizam e por que motivo, contribuindo assim para o entendimento das dinâmicas de institucionalização.

\section{Perspectivas "Oficiais" na Base do Novo Institucionalismo: Construtivismo Social e Etnometodologia}

Os neo-institucionais criticam a visão parsoniana do sistema social como ordem normativa, enfocando seu aspecto valorativo e excluindo os aspectos cognitivos, cultural e de orientação para ação. Para Parsons (citado por Heritage, 1984), o sistema de valores é um importante fator que contribui para a compreensão da organização e da ordem social. Essa ordem normativa é replicada pela apropriação da identidade dos indivíduos, o que os torna simples cumpridores de papéis operando com base nos valores pelos quais são socializados. A ação é analisada como produto de processos causais; estes, embora operem na mente dos atores, são considerados inacessíveis e incontroláveis por eles.

A principal crítica que o novo institucionalismo direciona ao funcionalismo de Parsons refere-se à falta da dimensão cognitiva que, segundo os representantes dessa abordagem, pode ser encontrada nos estudos de March e Cyert (1963), March e Simon (1958) e Simon (1976). O processo de tomada de decisão dentro das organizações se apresenta como um deslocamento do velho para o novo institucionalismo, de uma abordagem normativa para uma abordagem cognitiva, do comprometimento para rotina, da motivação para a lógica de seguimento das regras (Heritage, 1984; McSwite, 1998; Powell \& Dimaggio, 1990).

Outros paradigmas assumem papel central para a nova abordagem institucional, entre os quais se destaca o construtivismo social. Os principais representantes dessa abordagem são Berger e Luckmann (2001), que se interessam pela genética 
da verdade assumida como realidade (Canales, 1996) e abordam os processos de construção social da realidade, argumentando que a questão central da sociologia é descobrir como significados subjetivos se tornam facticidades objetivas.

Segundo Berger e Luckmann (2001) a relação entre o homem (produtor) e o mundo social (produto dele) é, e permanece sendo, uma relação dialética; ou seja, o homem (evidentemente não o homem isolado, mas em coletividade) e o seu mundo social atuam reciprocamente um sobre o outro. O produto reage sobre o produtor. A exteriorização e a reificação são momentos de um processo dialético contínuo, acompanhado pela interiorização, pela qual o mundo social objetivado é recolocado na consciência, durante a socialização. O que foi construído como realidade - construído pelo próprio intersubjetivo social - se apresenta simplesmente como realidade. Essa realidade e a sua própria superação inscrevem-se além do observável ou discutível pelos sujeitos que, depois de tê-la instituído, agora vivem a realidade dotada de legalidade própria. Reificada, a realidade socialmente produzida requer ser coberta por um segundo manto de verdade. As legitimações - desde a afirmação da verdade de uma máxima até os grandes relatos que trazem os universos simbólicos (religiosos, políticos etc.) - constituem uma escritura de segunda ordem que qualifica a realidade como justa ou boa (Canales, 1996).

Segundo Canales (1996), o conhecimento é objeto de estudo não apenas do construtivismo social, definido por Berger e Luckmann (2001) como sociologia do conhecimento comum, mas também da etnometodologia, definida por Garfinkel (1967) como método do conhecimento comum.

Etnometodologia é o método de conhecimento prático que investiga a maneira pela qual nós produzimos a realidade que consideramos como dada e óbvia; a análise dos processos formais por meio dos quais o ator cotidiano compreende sua ação no contexto onde está inserto. Durante a ação, o ator toma como dado certo conhecimento que considera ser sabido e manejado igualmente pelos outros. Essa base de conhecimento em comum - ativada em cada situação social assim como suas regras e operações, é objeto de uma pesquisa etnometodológica. Etno, considerando que estamos falando sobre conhecimento próprio à sociedade de referência do ator; e metodologia, considerando que estamos tratando de procedimentos formais de conhecimento e argumentação manejados pelo ator cotidiano.

Para Garfinkel (1967), aluno de Parsons, a ordem social é constituída como atividade prática no curso da interação diária e não deriva automaticamente de padrões compartilhados de valores e papéis sociais. Ele rejeita a visão de que os julgamentos comuns de atores sociais possam ser tratados como irrelevantes para a análise da ação e da organização social. 
É a negligência parsoniana relativa ao mundo do 'senso comum', no qual os atores escolhem o curso de ação com base em considerações e julgamentos detalhados práticos, que, por sua vez, são inteligíveis e explicáveis para outros, que, ao final, constitui o foco central e o ponto de partida para o tratamento que o Garfinkel dá à teoria da ação (Heritage, 1984, p. 34).

Garfinkel (1967) deslocou a imagem da cognição de um processo racional, quase científico, para um processo que opera, na maior parte, abaixo do nível da consciência: rotina e raciocínio prático, operado por regras reconhecidas somente quando são quebradas. Para ele, a ação é justificada principalmente após o fato, referindo-se a um estoque de descrições culturalmente disponíveis (Powell \& DiMaggio, 1990).

Conceitos como reificação, instituição e institucionalização se usam extensivamente pelos principais autores que representam a nova escola institucional. Na próxima parte deste capítulo, resgatamos estes conceitos cruciais da forma como eles são abordados nas perspectivas oficiais na base do novo institucionalismo.

\section{Reificação, Instituições e Institucionalização: Perspectivas CLÁSSICAS}

\section{Reificação}

O conceito de reificação é chave na perspectiva do construtivismo social. "A expressividade humana é capaz de objetivações (a tradução para reificação), isto é, manifesta-se em produtos da atividade humana que estão ao dispor tanto dos produtores quanto dos outros homens, como elementos de um mundo em comum" (Berger \& Luckmann, 2001, p. 53). A realidade da vida cotidiana não é cheia unicamente de reificações; é somente possível por causa delas. "Estou constantemente envolvido por objetos que 'proclamam' as intenções subjetivas de meus semelhantes, embora possa às vezes ter dificuldade de saber ao certo o que um objeto particular está "proclamando" (Berger \& Luckmann, 2001, p. 54). Da realidade produzida advém a realidade reificada. A realidade instituída das instituições torna-se realidade com direitos iguais à realidade física ou natural.

A análise de Berger e Luckmann inspirou diferentes estudos na linha do construtivismo social. Hacking (1999) critica o uso ingênuo da abordagem em diferentes pesquisas que precederam a publicação do seu livro nos EUA. A principal crítica reside no fato de que o processo de construção tem sido visto 
como resultado consciente dos processos de interação, quando, de fato, Berger e Luckmann trabalham com a dimensão inconsciente do processo.

Como Wenger (1998, p. 58) nos lembra, o termo reificação significa tornar-se coisa e, no idioma inglês, é utilizado para dizer que o que se tornou objeto concreto e material, não é propriamente concreto e material. O autor nós dá os exemplos da justiça representada como uma virgem cega, segurando uma balança, ou de expressões como as mãos da sorte.

No entanto o autor usa o termo reificação como "o processo de dar forma à nossa experiência, produzindo objetos que congelam essa experiência em "coisa"" (Wenger, 1998, p. 58), considerando essa coisa central a toda prática. Nesse sentido, as formas reificadas são vistas como consequiências de uma complexa rede de convenções, acordos, expectativas, compromissos, obrigações etc.

Com o termo reificação, pretendo cobrir uma ampla gama de processos que incluem o fazer, projetar, representar, nomear, codificar e descrever, assim como perceber, interpretar, usar, reutilizar, decodificar, e remoldar (...) aspectos da experiência e prática humana que são congelados em formas fixas e aos quais é dado o status de objeto (Wenger, 1998, p. 56).

Por outro lado, Hacking (1999), na sua crítica ao uso corrente do construtivismo social, reconhece que idéias construídas - tais como gênero, mulher imigrante etc. - não existem num vácuo, mas estão presentes num contexto social. De fato, idéias e classificações funcionam apenas numa matriz:

Vamos lembrar da matriz na qual uma idéia, um conceito ou coisa similar é formada. 'Matriz' não é mais perfeita para os meus propósitos do que a palavra 'idéia'. Deriva da palavra útero (berço), mas adquiriu uma série de outros sentidos - por exemplo, na álgebra avançada. A matriz na qual a idéia da mulher imigrante é formada é um complexo de instituições, defensores, artículos de jornais, advogados, decisões judiciais, procedimentos de imigração. Para não mencionar a infra-estrutura material, fronteiras, passaportes, uniformes, balcões de aeroportos, centros de detenção, edifícios de justiça, campos de férias para crianças de imigrantes. Alguém pode chamar esses elementos de social, porque seus significados são o que importam para nós, mas eles são materiais, e na sua pura materialidade fazem uma diferença substancial às pessoas (Hacking, 1999, p. 10-11).

\section{Instituições e Institucionalização}

Existem alguns pontos a serem enfatizados na definição de instituição: 
. O conceito refere-se a uma ampla gama de questões: costumes, práticas, relações, organizações ou comportamentos.

. Refere-se também a um padrão, isto é, a um modelo, a alguma coisa a ser imitada, seguida.

. Tem importância ou significância na vida da comunidade ou sociedade.

- Geralmente, é usado em referência a organizações também consideradas importantes ou relevantes em campos como educação, serviço público ou cultura.

Para o novo institucionalismo, instituições são consideradas como um tipo de convenção que assume o status de regra. As instituições são encontradas em todo lugar, desde o aperto de mão e o casamento, até departamentos de planejamento estratégico de grandes organizações. Essa definição é baseada na perspectiva etnometodológica, embora valha a pena lembrar que a agenda de pesquisa dessa escola nem sempre reflete esse compromisso paradigmático.

Por outro lado, a institucionalização é considerada como "o processo fenomenológico por meio do qual certas relações e ações sociais começam a ser consideradas como dadas" e um "estado de arte no qual certas relações sociais definem o que tem sentido e quais ações são possíveis" (Zucker como citado em Powell \& DiMaggio, 1990, p. 9).

Segundo Heritage (1984), para Parsons a institucionalização é um mecanismo fundamental, integrador do sistema social e da organização da ação. A institucionalização é conseqüência de processos pelos quais atores, em conformidade com os sistemas de valores de uma sociedade e temendo as conseqüências decorrentes do desvio, internalizam rumos de ação prescritos ou esperados como sendo apropriados ou certos. Por meio da internalização de padrões comuns de orientação para valores, o sistema de interação social pode ser estabelecido. Para Parsons, o foco da institucionalização é a ação. As instituições são vistas como um sistema de normas que regulam as relações entre os indivíduos e que definem como essas relações devem ser (Scott, 1995, p. 12).

Uma das principais críticas da visão parsoniana está relacionada à dimensão cognitiva: o saber do ator sobre as circunstâncias. Os relatos dos atores sobre a ação como inteligível e objeto de avaliação equilibrada que envolve justificação, culpa e outras questões morais, colocam o problema da importância que merece ser atribuída aos relatos que os atores oferecem sobre as razões de sua ação (Heritage, 1984). 
Para compreender a visão de Parsons sobre a ação institucionalizada é importante relacioná-la à teoria do conhecimento que lhe serve de base, o realismo analítico, que defende que pelo menos alguns dos conceitos gerais da ciência adequadamente captam aspectos objetivos do mundo externo. A análise parsoniana é também caracterizada:

(...) por uma teoria de verdade 'correspondente', no qual o conhecimento do ator é avaliado em termos de sua concordância com os "fatos da situação", conforme determinados pelo observador científico. Uma correspondência paralela de "teoria da linguagem" é também invocada, na qual linguagem é essencialmente considerada como um conjunto de nomes que podem ter significado intersubjetivo apenas na medida em que correspondências entre 'nomes' e 'coisas', 'signos' e 'referentes' são socialmente estabelecidas e adequadamente reproduzidas em atos de comunicação (Heritage, 1984, p. 29).

Numa linha mais subjetiva e influenciada pela fenomenologia inserem-se o construtivismo social, a etnometodologia e a contribuição de Schutz (1972, 1979).

Da perspectiva do construtivismo social a instituição representa o duplo status do social como algo subjetivo na sua origem e objetivo na sua manifestação. Instituído, na ordem social é questão de formas e sujeitos numa relação recursiva, na qual os sujeitos dão forma ao social e o social dá forma aos sujeitos. A cotidianidade pode ser entendida como a região onde as instituições se apresentam como realidade comum, de origem natural e de modo corrente (Canales, 1996).

$\mathrm{Na}$ proposta de Berger e Luckmann (2001), as instituições assumem o importante papel de mediadoras. "A instituição ocorre sempre que há uma 'tipificação' recíproca de ações 'habituais' por 'tipos' de atores” (Berger \& Luckmann, 2001, p. 79). As instituições implicam historicidade - não podem ser compreendidas sem que seja entendido o processo histórico em que foram produzidas - e controle - controlam a conduta humana, estabelecendo padrões previamente definidos de conduta, que a condicionam numa direção oposta às muitas outras direções que seriam teoricamente possíveis. Vale a pena lembrar que, destacando a dimensão do controle, Berger e Luckmann também dão um passo adiante, na direção do reconhecimento do papel do poder nas instituições.

Uma instituição é um modelo de referência do ator. Como modelo, compartilhado e não questionado, pode referir-se tanto à condição "moral" (da perspectiva de Durkheim) ou à condição epistêmica. Um modelo é, a princípio, um modelo do que é socialmente valorizado ou do que é socialmente real (Canales, 1996). 
Da perspectiva de Berger e Luckmann (2001), de Garfinkel (1967) e de Schutz (1972, 1979), as instituições são construções cognitivas. Esses autores sugerem que elas controlam a conduta humana, a priori, por meio de qualquer tipo de mecanismo ou sanção especificamente montada para apoiá-las. As instituições regulam a imagem da realidade para os sujeitos que atuam e participam em certa sociedade. Essas interpretações geradas tipificam atores e ações e circulam como saber comum de todos os sujeitos que participam dessa sociedade. É um senso de realidade que define os lugares e sentidos da relação identidade/mundo; são códigos de signos com os quais se conhece a realidade (Canales, 1996; Powell \& Dimaggio, 1990).

Acreditamos que as abordagens acima analisadas apresentam algumas lacunas resumidas a seguir.

- Considerando a classificação de Burrell e Morgan (1982) relativa à dimensão objetividade-subjetividade nas ciências sociais, é possível considerar que todas estas linhas compartilham como premissa crucial o subjetivismo, enfatizando a maneira como os humanos criam, modificam e interpretam o mundo no qual se encontram. Esta classificação, no entanto, não leva em consideração que a dicotomia objetividade-subjetividade também pode ser considerada uma dicotomia construída (ver a seguir) e que a materialidade também pode desempenhar papel importante no processo de construção da realidade. Acreditamos que as perspectivas não-dicotômicas, às quais recorremos a seguir, possam preencher esta lacuna.

As perspectivas acima destacadas enfatizam aspectos normativos, cognitivos ou valorativos para a compreensão de fenômenos como reificação, instituição e institucionalização. No entanto nenhuma delas aborda a questão do poder, a qual acreditamos seja uma dimensão importante na compreensão dos processos de emergência e institucionalização dos campos organizacionais.

Encontramos a resposta a estes questionamentos na contribuição de algumas perspectivas que, a seguir, serão denominadas de não-dicotômicas.

\section{A Contribuição das Perspectivas Não-Dicotômicas}

Nessa parte do trabalho defendemos o posicionamento baseado no fim da dicotomia objetividade-subjetividade e argumentamos que o conceito do discurso proposto por Foucault que opera com base no mesmo pressuposto - o fim da dicotomia objetividade-subjetividade - pode ser utilizado na compreensão das 
dinâmicas de institucionalização, oferecendo a vantagem de incorporação da dimensão do poder.

\section{A Questão da Dicotomia Objetividade-Subjetividade}

Consideramos que a principal diferença entre as abordagens anteriormente expostas e outras que analisam os processos de construção da realidade está nas pressuposições básicas sobre a dicotomia objetividade/subjetividade, traduzidas numa perspectiva realista ou idealista.

Por exemplo, na visão marxista esse processo está relacionado com a produção, a partir de condições materiais e objetivas (que são "dadas" na estrutura capitalista); enquanto na visão de Berger e Luckmann (2001), a reificação é um processo subjetivo de construção. Essa divisão, por sua vez, reflete uma problemática maior, que é a da dicotomia objetividade/subjetividade, profundamente enraizada no senso comum sobre o mundo. Nesse ponto, a contribuição do pragmatismo americano é extremamente importante. Autores como Rorty explicitamente propõem o fim dessa dicotomia, enquanto para os pós-estruturalistas franceses, especificamente Foucault, isso vai servir como um pressuposto implícito das suas contribuições.

Para muitos, a objetividade é a atitude natural do homem perante o mundo. $\mathrm{O}$ homem nasce num mundo real. Como Morente (1980) argumenta, para o realista existem as coisas, o mundo das coisas e o eu entre elas. $\mathrm{O}$ conhecimento reflete a mesmíssima realidade. A verdade se define pela adequação entre o pensamento e a coisa. Tal adequação se consegue mediante a reta formação de conceitos. A evolução - o próprio processo do pensamento realista - é uma correção contínua dos conceitos. No fundo de todo esse processo, sempre encontramos o mesmo postulado fundamental, segundo o qual "as coisas são inteligíveis: que as coisas são as que têm no seu próprio ser a essência, a qual é acessível ao pensamento, porque o pensamento se ajusta, coincide perfeitamente com elas" (Morente, 1980, p. 134). Isso quer dizer que os realistas acreditam que existem um, e apenas um, way the world is in itself (Rorty, 1999a).

Tal pensamento, que parte de Parmênides, culmina em Aristóteles e nos acompanha até hoje, tenta produzir fielmente a articulação mesma da realidade (Bhaskar, 1975).

(...) o homem espontâneo e natural é aristotélico; e se o homem é aristotélico, espontânea e naturalmente, nada tem de estranho o espetáculo que nos dá a história e que consiste em que, a partir de Aristóteles, pouco a pouco a concepção metafísica aristotélica do mundo e da vida vai se enraizando cada vez mais nos espíritos e nas almas, até tornar-se uma crença; uma crença que atinge o 
fundo mesmo do intelecto, o fundo mesmo da alma individual (Morente, 1980, p. 135).

Questionado pela existência de fatos históricos, o realismo entra em crise. Dessa crise nasce uma posição nova da filosofia, que considera que o pensamento humano é radical e essencialmente condicionado pelo tempo e pela história (Morente, 1980). A nova posição filosófica, conhecida como idealismo "volta as costas ao sentido comum; volta as costas à propensão natural e nos convida a realizar um exercício acrobático de uma extrema dificuldade, que consiste em pensar as coisas como derivadas do eu" (Morente, 1980, p. 141).

Não cabe entrar aqui em explanações históricas sobre a evolução do novo pensamento filosófico. Basta enfatizar que as duas correntes, que partem de postulados diferentes, ainda dirigem o pensamento de estudiosos e pesquisadores, sejam eles de organizações ou não. Elas geraram inúmeras perspectivas que competem hoje para o status de superioridade em termos metodológicos.

Existem duas possíveis respostas para o debate objetividade/subjetividade. A teoria de estruturação de Giddens e o construto teórico campus/habitus de Bourdieu se inserem na tentativa de oferecer uma síntese teórica objetividade/ subjetividade (Peci, 2003).

Por outro lado, a resposta do pragmatismo, que se apresenta como pressuposto básico deste artigo, considera que o debate realismo/anti-realismo deve ser deixado de lado. Vale a pena começar a explorar as possibilidades de uma nova perspectiva que, não reconhecendo essa dicotomia, oferece a vantagem de nos libertar das problemáticas objeto/subjeto e aparência/realidade, que têm dominado a filosofia desde Descartes (Rorty, 1999b). Uma vez assumida essa posição e começando a operar conforme essa nova perspectiva, outras dicotomias desmoronam: palavras/atos, conhecimento/ação, teoria/prática, espaço/tempo perdem sua razão de ser.

\section{Discurso na "Arqueologia do Saber": Formação, Prática, Poder e Campos}

Nesta parte do artigo argumentamos que o conceito de discurso proposto por Foucault pode ser utilizado na compreensão das dinâmicas de institucionalização, oferecendo a vantagem da incorporação da dimensão do poder.

É oportuno destacar que o conceito de discurso como "unidade" de conhecimento presente num período particular de tempo se baseia no fim da dicotomia objetividade/subjetividade. Foucault (1972) afasta-se de um 
posicionamento objetivista e/ou subjetivista. No estudo dos processos discursivos, Foucault (1972, p. 63) propõe "evitar as "coisas", elidir o momento das coisas mesmas, mas, sem se remeter à análise lingüística da significação. Na análise foucaultiana, "as palavras estão tão deliberadamente ausentes quanto as próprias coisas" (Foucault, 1972, p. 63-64).

(...) 'discursos', (...) não são, como poderia se esperar, um puro e simples entrecruzamento de coisas e palavras. (...) analisando discursos, vemos se desfazerem os laços aparentemente tão fortes das palavras e das coisas e separar um conjunto de regras próprias à prática discursiva. (....). Tarefa que consiste em não mais tratar os discursos como conjuntos de signos (de elementos significantes que remetem a conteúdos ou a representações) mas como práticas que formam sistematicamente os objetos de que falam (Foucault, 1972, p. 64).

Muitos outros exemplos que não reconhecem a dicotomia objetividade/ subjetividade são encontrados na obra de Foucault, demonstrando, dessa maneira, afinidade com a perspectiva pragmática americana. No entanto, atendendo aos propósitos deste estudo, vamos concentrar-nos no conceito de discurso.

Foucault (1972) emprega esse conceito para se referir às relações que propiciam o processo de formação dos objetos. Ele estuda o processo de formação discursiva, definido com base nesse conjunto de relações, tentando mostrar que qualquer objeto do discurso em exame encontra aí seu lugar, sua lei de aparecimento.

Estas relações são estabelecidas entre instituições, processos econômicos e sociais, formas de comportamento, sistemas de normas, técnicas, tipos de classificação, modos de caracterização; e essas relações não estão presentes no objeto; não são elas que são desenvolvidas quando se lhes faz a análise; elas não desenham a trama, a racionalidade imanente, essa nervura ideal que reaparece totalmente ou em parte quando o pensamos na verdade do seu conceito. Elas não definem sua constituição interna, do objeto mas o que lhe permite aparecer, justapor-se a outros objetos, situar-se em relação a elas, definir sua diferença, sua irredutibilidade e eventualmente sua heterogeneidade, enfim, de ser colocado em um campo de exterioridade (Foucault, 1972, p. 59-60).

Assim, as relações discursivas não são internas ao discurso, mas também não são relações exteriores ao discurso que limitariam, ou ao qual imporiam certas formas, ou forçariam em certas circunstâncias a enunciar certas coisas. Elas estão, de alguma maneira, no limite do discurso, caracterizando-o como prática. O discurso deve ser considerado como prática que sistematicamente forma os objetos sobre os quais fala, o conjunto de regras que são inerentes a uma prática 
que define a sua especificidade. Daí o uso corrente do conceito de práticas discursivas em pesquisas influenciadas pela perspectiva foucaultiana, que não deixa de ser uma tautologia. A palavra discurso, em si, já compreende a dimensão da prática.

Buscar a unidade de um discurso é buscar a dispersão de elementos, descrita em sua singularidade de determinar regras específicas, segundo as quais foram formados objetos, enunciações, conceitos, opções teóricas. A unidade do discurso reside nesse sistema que rege e torna possível a sua formação. Quando se fala de um sistema de formação, não se compreende somente a justaposição, a coexistência ou a interação de elementos heterogêneos (instituições, técnicas, grupos sociais, organizações perceptivas, relações entre discursos diversos), mas seu relacionamento pela prática discursiva (Foucault, 1972).

Com base em Nietzsche e numa linha muito próxima da perspectiva pragmática, Foucault incorpora a dimensão do poder na sua análise, falando sobre a política da verdade. Ele argumenta que o conhecimento foi inventado, isto é, não tem origem.

O conhecimento é o simples resultado da ação recíproca, encontro, junção, luta e compromisso entre os instintos. Alguma coisa é produzida, porque os instintos se encontram, brigam entre si, e, ao final da sua batalha, finalmente chegam a um compromisso. Esse compromisso é o conhecimento (Gordon, 1994, p. 8).

Da mesma maneira que o conhecimento não é de modo algum relacionado com a natureza, não deriva da natureza humana, ele também não se relaciona com o mundo a ser conhecido, não tem afinidade com esse mundo a ser conhecido, com as coisas. O mundo não tenta imitar o homem; o mundo não conhece leis. Portanto, aqui, temos a primeira ruptura entre conhecimento e as coisas. Nesse sentido, se realmente quisermos saber o que é o conhecimento, compreendê-lo na sua raiz, na sua produção, não devemos olhar os filósofos, mas os políticos. Podemos compreender o que o conhecimento é, examinando as relações de luta e poder; a maneira pela qual coisas e homens se odeiam, brigam, tentam dominar um ao outro, exercer relações de poder sobre o outro. Considerando que não existe conhecimento em si, devemos tentar compreender a política da verdade.

Campo discursivo - onde é contemplada a dimensão tempo/espaço - é outro conceito importante em Foucault. Campo é o espaço onde se desenvolvem os acontecimentos discursivos. É no campo onde se manifestam, se cruzam, se emaranham e são especificadas as questões do ser humano, da consciência e do sujeito (Foucault, 1972, p. 25). Temporalidade e espacialidade tornam-se uma coisa só no conceito de campo. Campo é tempo e espaço, ser e devir, estrutura e história, formação e (trans)formação. 
Propomos, neste artigo, incluir no âmbito da perspectiva institucional a idéia de campo discursivo, em substituição à de matriz ou rede, normalmente presente para contextualizar o locus e a forma do movimento dos atores na perspectiva institucional. É dentro de campos discursivos que os processos de reificação e institucionalização ocorrem. O processo de formação discursiva trans(forma) os objetos. Relacionando os processos de institucionalização com o discurso, é aberto espaço para incorporar uma dimensão negligenciada da análise institucional, que é a dimensão do poder. Incorporando essa dimensão, podemos dar um passo à frente na compreensão dos processos de seleção institucional, ou simplesmente, responder à pergunta: quais práticas se institucionalizam e por que elas e não outras?. Esse é um ponto importante para compreender a própria configuração de um campo já institucionalizado. O entendimento das disputas ocorridas durante o processo de formação de um campo pode identificar, a partir de uma análise histórica como a de Vieira e Carvalho (2003), os principais elementos explicativos da sua atual configuração. Neste artigo, o entendimento é de que esses elementos são elementos discursivos, ou discursos que representam diferentes poderes. Esta abordagem antecipa-se em Clegg (1989), com o conceito de poder que flui por meio de pontos de passagens que os atores num campo constantemente em mudança como resultado de contingências externas e de lutas internas com o poder e sua circularidade - tentam estabilizar.

Assim como na abordagem pragmática, Foucault destaca o papel dos conhecimentos como úteis e necessários ao exercício do poder, sendo que eles são úteis e não falsos, como a tradição marxista tem tentado demonstrar. Para Gordon (1994), um dos pontos-chave em Foucault é que ele ressalta que o que é mais interessante entre as relações do poder com o conhecimento não é a detecção de conhecimento falso, espúrio, mas o papel de conhecimentos que são valorizados e efetivos por causa de sua segura eficácia instrumental. Foucault usa a palavra savoir - utilizada para conotar o conhecimento próximo ao know-how (uma maneira de tornar um problema tratável ou um material manejável). Esse tipo médio de conhecimento, que pode não ser rigorosamente científico, demanda certo grau de ratificação dentro de um grupo social, além de conferir alguns benefícios sociais.

A idéia de instrumentabilidade das verdades - isto é, de conhecimentos verificada em James (1997), é muito similar ao interesse de Foucault pelo papel dos conhecimentos como úteis e necessários ao exercício do poder. Isso ocorre porque os conhecimento são praticamente úteis (practically serviceable) e não porque são falsos, como a tradição marxista tenta mostrar. Contudo, diferentemente de Foucault, para James o foco da análise continua a ser o sujeito.

Foucault expande o conceito além do sujeito para o nível do discurso. Sem 
dúvida, essa noção de praticabilidade, verificada em Foucault, tem a vantagem de oferecer outra dimensão à análise da formação de campos discursivos: a dimensão do poder que, de fato, também não é explicitamente reconhecida na abordagem pragmática.

Para Foucault, o poder não é capaz de promover e explorar conhecimentos espúrios, mas o exercício racional do poder tende a fazer uso pleno dos conhecimentos capazes da máxima eficácia instrumental. Assim, duas idéias presentes nas investigações de Foucault foram a produtividade do poder (relações de poder integram os modernos apparatus de produção social e estão relacionadas aos programas ativos para a parte fabricada da substância coletiva da própria sociedade) e a constituição da subjetividade por meio de relações de poder (o impacto individual das relações de poder não se limita à repressão pura, mas também inclui a intenção de ensinar, moldar condutas, implantar gradualmente formas de consciência própria e identidades) (Gordon, 1994).

\section{A Dimensão Negligenciada: o Poder}

Nesse ponto, vale a pena abordar novamente a questão da dicotomia objetividade/subjetividade para ressaltar que a dimensão do poder está incluída nos próprios pressupostos que lhe servem de base.

Muitos pós-estruturalistas concordariam com a narrativa histórica de Morente (1980) que visa analisar o processo de estabelecimento da dicotomia objetividade/ subjetividade, mas argumentariam que tal processo é essencialmente político (Catlaw, 2002; Keller, 1995b; Latour, 1990, 1999).

Para Latour (1999, p. 15), a existência isolada, não-histórica, desumana e objetiva do mundo exterior foi dada para combater as massas, as massas desgovernáveis que Sócrates e outros foram tão rápidos em invocar para justificar a procura de uma força tão grande que fosse capaz de reverter o poder de dez mil tolos. Latour (1999) vai além e denuncia também o projeto político que visou à substituição do ego transcendental com a sociedade. Para ele, foi nesse momento "(...) que os preconceitos, categorias, e paradigmas de um grupo de pessoas que moravam juntas determinaram as representações de cada um deles" (Latour, 1999, p. 6).

Nada no mundo tinha que passar por tantos intermediários para chegar na mente individual. As pessoas foram fechadas não apenas na prisão das suas próprias categorias, mas também naquelas do seu grupo social. Em segundo lugar, esta 'sociedade' em si não era mais que uma série de mentes-em-tonel; com certeza, muitas mentes e muitos tonéis, mas, cada um desses, ainda olhando 
para um mundo exterior. Que melhoria! Se os prisioneiros não continuavam a se localizar em celas individuais, eles eram agora confinados no mesmo dormitório, na mesma mentalidade coletiva. Em terceiro lugar, o próximo deslocamento, do Ego para culturas múltiplas, expôs a única coisa boa sobre Kant, isto é, a universalidade das categorias a priori, o único pedacinho de certeza absoluta que ele foi capaz de manter. Daqui para diante, ninguém era fechado na mesma prisão; agora eram muitas prisões, incomensuráveis, não conectadas. Não foi apenas a mente que desligou-se do mundo, mas cada mente coletiva, cada cultura, desconectou-se das outras (Latour, 1999, p. 15).

Como já vimos, Foucault não apenas reconhece essa dimensão política na dicotomia objetividade/subjetividade, mas também reúne cuidadosamente dimensão do poder e análise do discurso. O conceito de poder não está presente apenas na análise foucaultiana. É por meio das relações de poder que o próprio processo de formação discursiva se torna possível.

\section{Rediscussão de Alguns Conceitos}

A partir da perspectiva clássica da institucionalização, podemos chegar à conclusão errada de que tudo, pelo menos teoricamente, apresenta uma potencialidade de institucionalização. Especialmente quando usamos a noção de instituição como sinônimo de entidade real (por exemplo, uma organização como a Capes, no campo educacional no Brasil) podemos ser levados a considerar o processo de institucionalização ou mudança institucional como um processo consciente e simples. De fato, apenas certas práticas tornam-se institucionais, e o novo institucionalismo não pode oferecer respostas a esse processo seletivo.

Com base no pragmatismo, destacamos que as práticas institucionalizadas são práticas que funcionam, que são boas para nós; mas este artigo propõe ir além, ao operar com base no conceito de discurso e considerar que prática significa operar dentro das relações de poder e servir a essas relações de poder. A institucionalização ocorre dentro de campos discursivos predominantes numa dada sociedade. Propondo que os processos institucionais ocorrem dentro de campos discursivos, aqui, o argumento é o de que estes estão inconscientemente servindo à produtividade das relações de poder existentes nesses campos. Práticas que são institucionalizadas são práticas que funcionam, ou seja, que são necessárias e úteis ao exercício do poder. Esses discursos (práticas) são chamados neste estudo de discursos práticos, visando contemplar a dimensão de praticabilidade. 
Keller (1995b) contribui para a filosofia da ciência juntando a concepção pragmática e foucaultiana na análise de formação de novos campos científicos. No estudo de formação do campo científico da genética nos EUA, a autora desenvolve um corpo teórico interessante em termos do papel da linguagem e das dinâmicas da institucionalização. No entanto ela não enfoca simplesmente a língua (particularmente, o papel das metáforas), mas destaca as complexas redes de influências e interação que se estabelecem entre normas, desenvolvimentos técnicos e metáforas. A força das expressões descritivas deriva do papel das metáforas na construção da semelhança e da diferença, definindo semelhanças familiares que formam a base utilizada para categorizar fenômenos naturais e motivar a realização de determinados experimentos ou a construção de determinados dispositivos técnicos. Nem todas as metáforas são igualmente úteis ou cativantes, ou igualmente práticas. A efetividade de uma metáfora depende das convenções sociais compartilhadas e também pela autoridade convencionalmente concedida àqueles que a usam, isto é, às instituições. Uma metáfora socialmente efetiva há 20 anos pode não continuar efetiva hoje, em parte por causa das transformações dramáticas nas ideologias (como por exemplo, de gênero), ou seja, discursos prevalecentes.

A efetividade das metáforas científicas depende não apenas dos recursos sociais disponíveis, mas também da disponibilidade dos recursos técnicos e naturais. Algumas metáforas podem ser cognitiva e tecnologicamente mais produtivas que outras. E, também, podem produzir efeitos diferentes. $\mathrm{Na}$ abordagem da Keller (1995b), a técnica científica não apenas contribui, mas também se produz pelo discurso. O tráfego entre metáforas e máquinas tem efeitos transformadores nos próprios termos das histórias sociais ou das técnicas científicas.

Nesse esquema, a distinção humanos/não-humanos não existe (Latour, 1999) e os aspectos (trans)formativos do novo campo dependem dos discursos. Os objetos científicos, foco da análise da Keller (1995b), foram constituídos e, ao mesmo tempo, transformados pelos discursos.

Finalizando, é possível responder à indagação do Powell e DiMaggio (1990, p. 38) "considerando que tudo o que entra numa interação humana pode tornar-se base de uma tipificação compartilhada, por que algumas tipificações (nação, família, propriedade privada) são mais presentes que outras (município, primos de segundo graus)?" Uma teoria cognitiva de ação não pode dar conta das respostas diferentes em termos afetivos e normativos. No entanto uma teoria do discurso pode reunir as dimensões discutidas em outras perspectivas, seja afetiva, normativa, cognitiva e política. A presença dessas tipificações dependerá de como são situadas no campo relacional e poderoso dos discursos. 


\section{ConClusão}

Embora a abordagem neo-institucional esteja em voga na área de estudos organizacionais, ela apresenta lacunas em termos de microfundamento de ação. Ainda, a principal contribuição dessa perspectiva se verifica mais na análise das instituições - tomando-as como dadas - do que na análise dos processos de institucionalização. Neste artigo, argumenta-se que o referencial oferecido por Foucault pode contribuir para fortalecer o microfundamento de ação da escola institucional e, paralelamente, a compreensão dos processos de institucionalização.

Todos os representantes oficiais do institucionalismo reconhecem que esses processos não se dão no vácuo. Pelo contrário, por meio de expressões como rede e matriz, visam ressaltar a complexidade dos processos de institucionalização. No entanto o problema reside nos pressupostos básicos dessas perspectivas que, deliberadamente ou não, se posicionam de maneira diferente quanto à dicotomia objetividade/subjetividade. Sob o argumento de que estabelecer essa dicotomia serve a interesses políticos, este artigo defende a superação dessa dicotomia, vendo no discurso de Foucault uma alternativa para se compreender os processos de institucionalização.

Não é por acaso que o conceito de discurso se torna uma alternativa às correntes oficiais do institucionalismo, discurso que, para Foucault, supera essa mesma dicotomia, dá maior dinamismo ao estudo dos processos de institucionalização, reúne as dimensões temporal e espacial por meio do conceito de campo discursivo, aglomerando todas as dimensões analisadas, algumas delas por vezes negligenciadas, na análise institucional: a normativa, a cognitiva, a afetiva e a do poder. Os discursos não são um puro entrecruzamento de coisas e de palavras. Não são conjuntos de signos, mas práticas que formam sistematicamente os objetos de que falam. Situado além das coisas e das palavras, o conceito de discurso supera o debate objetividade/subjetividade e nos abre outro espaço de discussão, que concentra a atenção nas regras de formação, nas relações de poder que (trans)formam os campos. O conceito de discurso contempla a complexidade dos processos de institucionaliz(ação) e contribui em termos de fundamentos da análise institucional - dessa vez, sem a divisão baseada na dicotomia micro/macro.

O conceito de praticabilidade apresenta-se como chave na compreensão dos processos de institucionaliz(ação). Esse conceito, estabelecido pelo pragmatismo americano, está presente também na etnometodologia de Garfinkel. Entretanto optamos por utilizar esse conceito conforme Foucault o utiliza, incorporando a dimensão do poder e argumentando que a eficácia instrumental dos conhecimentos 
tem a ver com o papel que estes desempenham como praticamente úteis e necessários ao exercício do poder.

Assim, é possível dar um passo à frente na compreensão dos aspectos seletivos da institucionalização e captar como esses processos servem às relações de poder existentes num campo discursivo. Práticas que se institucionalizam são práticas que funcionam, ou seja, práticas necessárias e úteis às relações de poder.

Por fim, é defendida aqui a idéia de que a área dos estudos organizacionais poderá beneficiar-se de uma visão mais abrangente dos processos de institucionalização, que inclui a dimensão do poder, em vez de considerar as instituições como variáveis dadas e imutáveis. Clegg (1989) oferece uma base para este tipo de análise e este trabalho serve para elaborar mais detalhadamente alguns dos seus fundamentos filosóficos. Contudo deve ser destacado que, com base na abordagem teórica proposta, não é possível encontrar respostas na busca por explicações causais. O mecanismo causal é também uma verdade recentemente incorporada no discurso do poder por modernistas como Hobbes (1968). Certamente, se consideradas as pesquisas empíricas, demanda-se uma perspectiva histórica que visa apreender os principais discursos que constituem, transformam, e são transformados pelos nossos objetos de investigação, entre os quais certamente as organizações ocupam lugar central. Mas é preciso encarar tal empreendimento com certa modéstia, reconhecendo os limites do congelamento desse conceito tão dinâmico quanto o discurso, mesmo numa tentativa de pesquisa empírica.

\section{Artigo recebido em 07.05.2004. Aprovado em 23.09.2004.}

\section{ReferênCIAS BibliográficAs}

Berger, P. L., \&

Luckmann, T. (2001).

A construção social da realidade (20th ed.). Petrópolis: Vozes.

Bhaskar, R. (1975).

A Realist Theory of Science. Leeds: Leeds Books.
Burrell, G., \&

Morgan, G. (1982).

Sociological paradigms and organisational analysis. London: Heinemann.

Canales, M. (1996).

Sociología de la vida cotidiana. Recuperado em 25 maio, 2002, de http://www.uchile.cl/facultades/ csociales/excerpta/canales.htm 
Catlaw, T. J. (2002).

When "the people" commit suicide: new adventures in post-mortem public administration. Annual Conference of The European Group For Public Administration. Postdam, Alemanha,

Clegg, S. R. (1989).

Frameworks of Power. London: Sage.

Foucault, M. (1972).

A arqueologia do saber. Lisboa, Porto: Vozes.

\section{Garfinkel, H. (1967)}

Studies in ethnometodology. Englewood Cliffs, NJ: Prentice-Hall Inc.

Gordon, C. (1994).

Introduction. In: J. D. Faubion (Ed.). Michel Foucault: power. New York: The New York Press.

Hacking, I. (1999).

The social construction of what? London: Harvard University Press.

Heritage, J. (1984).

Garfinkel and ethnomethodology. New York: Polity Press.

Hobbes, T. (1968).

Leviathan. Harmondsworth: Penguin.

James, W. (1997).

What pragmatism means. In: L. Menand. Pragmatism: a reader. New York: Vintage.

Keller, E. F. (1995b).

Refiguring life: metaphors of twentieth-century biology. New York: California University Press.
Latour, B. (1990, January/March).

Portmodern? No, simply amodern! Steps towards an anthropology of science. Studies in History, Philosophy and Science, 21(1), 145171.

Latour, B. (1999).

Pandora's hope: essays on the reality of science studies. Cambridge, Massachusetts, London, England: Harward University Press.

March, J. G., \&

Simon, H. A. (1958).

Organizations. New York: Wiley.

March, J. G., \&

Cyert, R. M. (1963).

A behavioral theory of the firm. Englewood Cliffs, N. J.: Prentice-Hall.

McSwite, O. C. (1998, September).

The new normativism and the discourse movement: a meditation. Administrative Theory and Praxis, 20(2), 377-381.

Morente, M. G. (1980).

Fundamentos de filosofia (8a ed.).

São Paulo: Mestre Jou.

Peci, A. (2003, Janeiro/Março).

Estrutura e ação nas organizações. Revista de Administração de Empresas, 43(1), 24-35.

Powell, W. W., \&

DiMaggio, P. J. (Eds.). (1990).

The new institutionalism in organizational analysis. Chicago: University of Chicago Press. 
Rorty, R. (1999a).

A pragmatist view of contemporary analytic philosophy. Recuperado em 26 novembro, 2002, de http:// www.stanford.edu/ rrorty/ pragmatistview.htm

Rorty, R. (1999b).

Analytic philosophy and transformative philosophy. Recuperado em 26 novembro, 2002, de http://www.stanford.edu/ rrorty/ analytictrans.htm

Schutz, A. (1972).

Fenomenología del mundo social: introducción a la sociologia comprensiva. Buenos Aires: Paidos.

Schutz, A. (1979).

Fenomenologia e relações sociais. Rio de Janeiro: Zahar.
Scott, R. W. (1995).

Institutions and organizations. Thousand Oaks: Sage.

Simon, H. A. (1976).

Administrative behavior: a study of decision-making processes in administrative organization (3rd ed.). New York: Macmillan.

Vieira, M. M. F., \&

Carvalho, C.A. (2003).

Campos organizacionais: de wallpaper à construção histórica do contexto de organizações culturais em Porto Alegre e em Recife. Anais do Encontro Nacional dos Programas de Pós-Graduação em Administração, Rio de Janeiro, RJ, 27.

Wenger, E. (1998).

Communities of practice: learning, meaning and identities. Cambridge: Cambridge University Press. 
